\title{
A late complication of pectus excavatum repair
}

\author{
R. McWilliams, T. Hooper and R. Lawson
}

Department of Cardiothoracic Surgery, Wythenshawe Hospital, Manchester, UK

\begin{abstract}
Summary: We report a late complication of pectus excavatum repair which highlights the importance of a chest X-ray in evaluating chest pain in patients who have had previous chest surgery. It also raises the question of whether or not implanted wires should be electively removed following bony union.
\end{abstract}

\section{Introduction}

Pectus excavatum repair may involve the implantation of sternal and retrosternal wires. If not subsequently removed, there remains the possibility that migration of these wires may cause further morbidity. Such a possibility must be considered when such a patient presents with chest symptoms. We report an unusual case of pleuritic chest pain related to fracture and migration of a restrosternal wire, which to our knowledge has not been previously reported.

\section{Case report}

A 22 year old male presented to the casualty department complaining of a sudden onset of right-sided chest pain. The pain came on whilst performing heavy manual work, and was intermittent, pleuritic and varied in position with changes in posture. On one occasion there was associated haemoptysis. Four years previously the patient had undergone pectus excavatum repair based on the technique described by Ravitch. ${ }^{1}$ Physical examination revealed decreased expansion and breath sounds on the right side of the chest but was otherwise unremarkable. Chest X-ray revealed sternal wires as evidence of the previous pectus repair, and also demonstrated a free piece of wire at the right costophrenic angle (Figure 1). The wire was localized by postero-anterior and lateral chest $\mathrm{X}$-rays and under general anaesthesia a limited thoracotomy over the ninth interspace was per-

Correspondence: R.G. McWilliams, F.R.C.S., Countess of Chester Hospital, Liverpool Road, Chester, UK. Accepted: 1 November 1991 formed. The wire, lying free in the pleural cavity, was retrieved and the patient made a complete recovery.

\section{Discussion}

Social embarrassment is the main indication for operative intervention in pectus excavatum defor- 8 mity. The Ravitch repair involves a midline incision down to the sternal periosteum. ${ }^{1}$ The pectoral muscles are reflected laterally and the costal car-? tilages exposed. All cartilages for the length of the deformed segment are resected subperichondrially. The xiphisternum is detached and the sternum is then divided transversely in its upper part and a wedge excised anteriorly. The sternum is realigned and repaired with two wire sutures. The xiphisternum is similarly reattached. The various perichondrial tunnels are repaired with catgut. Wires are placed behind the sternum and underneath the pectoral muscles with the aim of holding the sternum forward until the osteotomy has healed.

Migration of residual wire, if not electively removed, is a potential complication. Intrathoracic migration in other situations has been reported. A case of a wire migrating from the sternoclavicular joint to the pericardial cavity has been reported, as has transbronchial migration of inhaled foreign bodies to the pleural cavity causing empyema. ${ }^{2,3}$

In the present report a second operative procedure was required to deal with a complication of the Ravitch-type repair, and we believe that this case raises two important considerations. Firstly, it highlights the importance of an awareness that foreign-body migration, long after the original operation, may account for late symptoms and, secondly, the issue of whether such retrosternal wires should be subsequently removed as an elective procedure to avoid such a complication. 


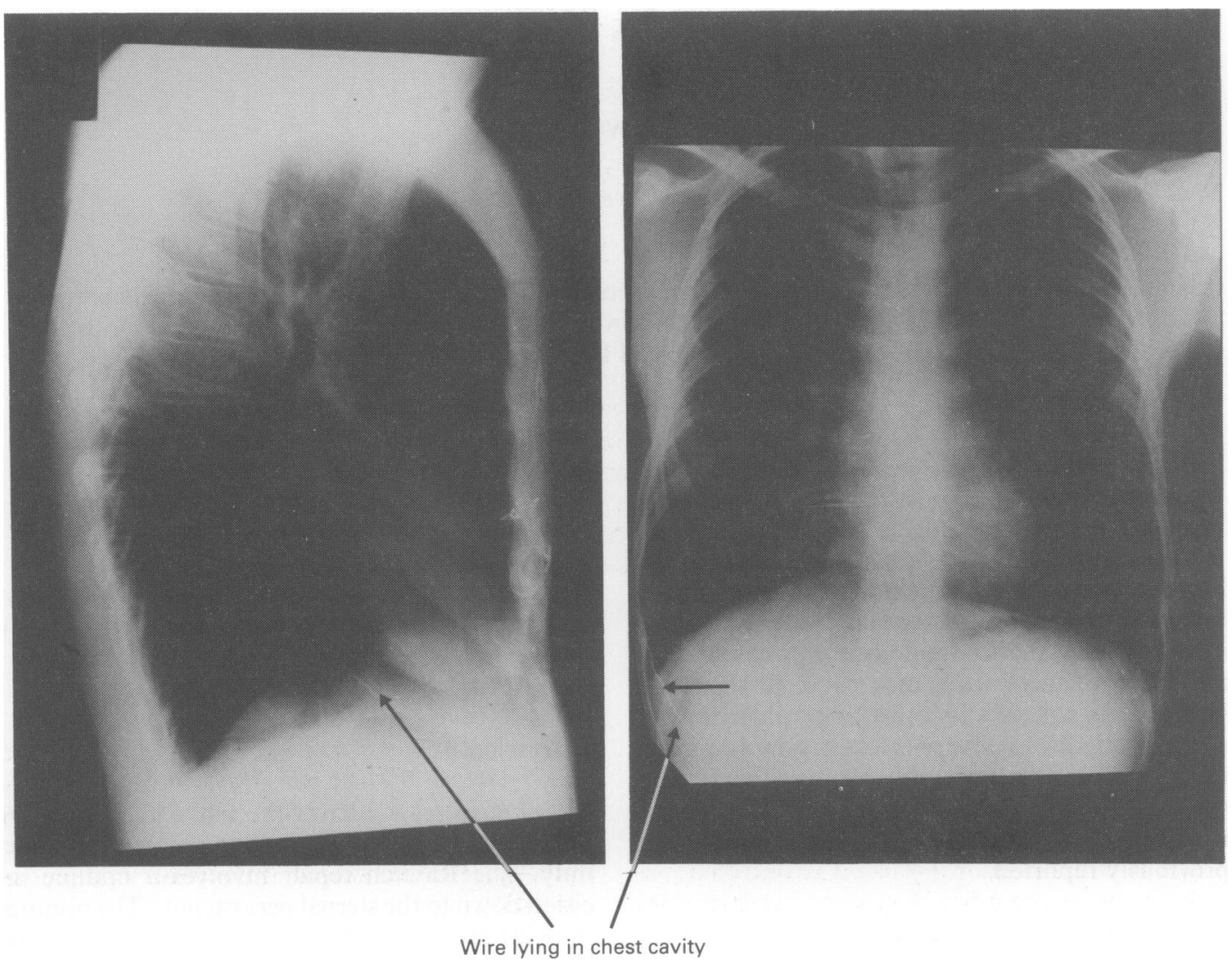

Figure 1 Lateral (a) and posteroanterior (b) X-ray showing wire lying in chest cavity.

\section{References}

1. Ravitch, M. Technical problems in the operative correction of pectus excavatum. Ann Surg 1965, 162: 29-33.

2. Fowler, A.W. (Letter to the Editor). Injury 1981, 13: 261-262.

3. Yellin, A., Tomer, A., Zwas, S.T., Hassin, D., Lieberman, Y.\& Bank, H. An unusual case of empyaema: intra pleural migration of an inhaled oat head in an adult. Thorac Cardiovasc Surg 1983, 31: 317-319. 